ARTICLE

\title{
Tuning the selectivity of catalytic nitriles hydrogenation by structure regulation in atomically dispersed Pd catalysts
}

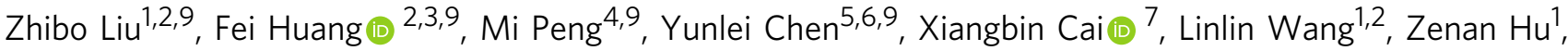

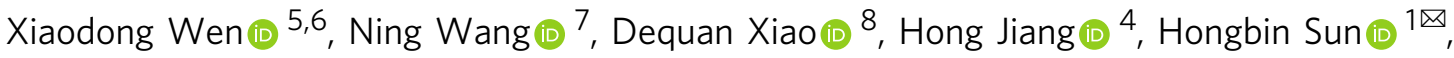 \\ Hongyang Liu (i) ${ }^{2,3 凶} \&$ Ding Ma (i) ${ }^{4 凶}$
}

The product selectivity in catalytic hydrogenation of nitriles is strongly correlated with the structure of the catalyst. In this work, two types of atomically dispersed Pd species stabilized on the defect-rich nanodiamond-graphene (ND@G) hybrid support: single Pd atoms $\left(\mathrm{Pd}_{1} / \mathrm{ND} @ \mathrm{G}\right)$ and fully exposed Pd clusters with average three Pd atoms $\left(\mathrm{Pd}_{n} / \mathrm{ND} @ \mathrm{G}\right)$, were fabricated. The two catalysts show distinct difference in the catalytic transfer hydrogenation of nitriles. The $\mathrm{Pd}_{1} / \mathrm{ND} @ \mathrm{G}$ catalyst preferentially generates secondary amines (Turnover frequency (TOF@333K $709 \mathrm{~h}^{-1}$, selectivity $>98 \%$ ), while the $P d_{n} / N D @ G$ catalyst exhibits high selectivity towards primary amines (TOF@313 K $543 \mathrm{~h}^{-1}$, selectivity $>98 \%$ ) under mild reaction conditions. Detailed characterizations and density functional theory (DFT) calculations show that the structure of atomically dispersed Pd catalysts governs the dissociative adsorption pattern of $\mathrm{H}_{2}$ and also the hydrogenation pathway of the benzylideneimine (BI) intermediate, resulting in different product selectivity over Pd $/$ $/ N D @ G$ and $P d_{n} / N D @ G$, respectively. The structure-performance relationship established over atomically dispersed Pd catalysts provides valuable insights for designing catalysts with tunable selectivity.

\footnotetext{
${ }^{1}$ Department of Chemistry, Northeastern University, Shenyang 110819, P. R. China. ${ }^{2}$ Shenyang National Laboratory for Materials Science, Institute of Metal Research, Chinese Academy of Sciences, Shenyang 110016, P. R. China. ${ }^{3}$ School of Materials Science and Engineering, University of Science and Technology of China, Shenyang 110016, P. R. China. ${ }^{4}$ Beijing National Laboratory for Molecular Sciences, College of Chemistry and Molecular Engineering and College of Engineering, and BIC-ESAT, Peking University, Beijing 100871, P. R. China. ${ }^{5}$ State Key Laboratory of Coal Conversion, Institute Coal Chemistry, Chinese Academy of Sciences, Taiyuan 030001, P. R. China. ${ }^{6}$ University of Chinese Academy of Science, No. 19A Yuanquan Road, Beijing 100049, P. R. China. 7 Department of Physics and Center for Quantum Materials, Hong Kong University of Science and Technology, Clear Water Bay, Kowloon, Hong Kong SAR, P. R. China. ${ }^{8}$ Center for Integrative Materials Discovery, Department of Chemistry and Chemical Engineering, University of New Haven, 300 Boston Post Road,

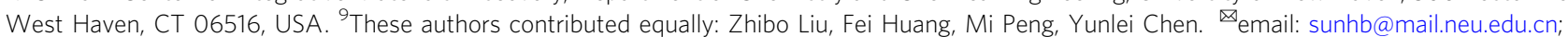
liuhy@imr.ac.cn; dma@pku.edu.cn
} 
A mines, both primary and secondary amines, are important raw materials in the synthesis of bioactive molecules in pharmaceuticals synthesis. There are many methods developed and utilized in both industry and academia to obtain amines, such as amination of aryl halides or alcohols, reductive amination of aldehydes or ketones, hydroamination of olefins or alkynes, hydrogenation of nitriles, alkylative amination, and basepromoted mono-N-alkylation ${ }^{1-5}$. Among them, hydrogenation of nitriles has attracted extensive attention. However, owing to the high thermodynamic stability of nitriles, hydrogenation of nitriles to target chemicals is difficult. Moreover, catalytic hydrogenation of nitriles yields complex products, including primary, secondary amines, imines, tertiary amines, and even by-products from hydrogenolysis ${ }^{6-8}$. Therefore, it is quite desirable to develop highly effective catalysts, especially those that can precisely control the product selectivity towards nitrile hydrogenation. In this regard, metal-based homogeneous catalysts such as $\mathrm{Ir}^{9}, \mathrm{Rh}^{10}$, $\mathrm{Ru}^{11}$, and $\mathrm{Re}^{12}$ have been widely applied in catalytic hydrogenation of nitriles because of their good activity and selectivity. However, separating the homogeneous catalysts from the product mixture is difficult, which makes the recycle of these expensive catalysts less feasible. To circumvent the reusability problems, using heterogeneous solid catalysts is a possible solution ${ }^{13-17}$. Nevertheless, unlike homogeneous catalysts that possess controllable active sites and coordination environments, rationally tuning the products distribution over heterogeneous catalysts has always been a challenge, owing to their heterogeneity in morphology and active site distribution and the variation in local coordination environment. Therefore, developing well-defined heterogeneous catalysts with high activity and good selectivity is an essential way to explore the structure-performance relationship of catalyst in the hydrogenation of nitriles.

In recent years, fully exposed cluster catalyst (FECC) contains atomically dispersed metal atoms on the support as the catalytic active sites have received increasing attention. FECCs offer diverse surface sites formed by an ensemble of metal atoms, comparing with single-atom catalyst ${ }^{18-22}$, it not only provides maximized atom utilization but also possesses rich active sites and easily identified coordination structures. FECC is so highly dispersed that all the metal atoms within it are available for the adsorption and transformation of reactants. As its stable metal loading can be higher than that of SAC, the FECC usually exhibits higher mass specific activity than the SAC, which is critically important for industrial applications ${ }^{23-30}$, providing a feasible approach to study the relationship of structure-performance of the hydrogenation of nitriles.

In this paper, we fabricate two kinds of atomically dispersed catalysts, single $\mathrm{Pd}$ atoms $\left(\mathrm{Pd}_{1} / \mathrm{ND} @ \mathrm{G}\right)$ and fully exposed $\mathrm{Pd}$ clusters with an average atomicity of three $\mathrm{Pd}$ atoms $\left(\mathrm{Pd}_{n} / \mathrm{ND} @ \mathrm{G}\right)$, both of which are immobilized on the defect-rich nanodiamond-graphene hybrid support (ND@G) $)^{31-33}$. The catalytic performance in the transfer hydrogenation of nitriles with $\mathrm{NH}_{3} \cdot \mathrm{BH}_{3}$ (AB) as the hydrogen donor was evaluated over $\mathrm{Pd}_{1} / \mathrm{ND} @ \mathrm{G}$ and $\mathrm{Pd}_{n} / \mathrm{ND} @ \mathrm{G}^{16,34,35}$. We found that secondary amines are preferentially obtained over $\mathrm{Pd}_{1} / \mathrm{ND} @ \mathrm{G}$, whereas primary amines are selectively generated over $\mathrm{Pd}_{n} / \mathrm{ND} @ \mathrm{G}$. To explain the differences, we further carried out density functional theory (DFT) calculations to elucidate the different mechanisms of the two Pd catalysts induced by structural variation and to better understand their drastically different catalytic performance.

\section{Results}

Synthesis and characterization of $\mathbf{P d}_{1} / \mathrm{ND} @ \mathrm{G}$ and $\mathbf{P d}_{n} / \mathrm{ND} @ \mathrm{G}$. The atomically dispersed $\mathrm{Pd}_{1} / \mathrm{ND} @ \mathrm{G}$ and $\mathrm{Pd}_{n} / \mathrm{ND} @ \mathrm{G}$ were prepared by a deposition-precipitation strategy. Except for different loading amounts of Pd species, no difference was observed in physicochemical structures of two samples (see Supplementary Table 1). The X-ray diffraction (XRD) patterns of $\mathrm{Pd}_{1} / \mathrm{ND} @ \mathrm{G}$ and $\mathrm{Pd}_{n} / \mathrm{ND} @ \mathrm{G}$ exhibit characteristic peaks of ND@G; no diffractions associated with Pd were observed, indicating that the Pd species were highly dispersed in these two samples (Supplementary Fig. 2a). The aberration-corrected highangle annular dark-field scanning transmission electron microscopy (AC-HAADF-STEM) images display detailed structures of as-prepared Pd species on ND@G (see Supporting Information for the ND@G support, Supplementary Fig. 1) ${ }^{36}$. For $\mathrm{Pd}_{1} / \mathrm{ND} @ \mathrm{G}$ (Fig. 1a, b), all Pd single atoms were uniformly distributed on the support. Due to some uncontrollable factors in the preparation process, it is inevitable that there are a few close Pd metal atoms in the $\mathrm{Pd}_{1} / \mathrm{ND} @ \mathrm{G}$ catalysts. While in $\mathrm{Pd}_{n} / \mathrm{ND} @ \mathrm{G}$ (Fig. $1 \mathrm{c}, \mathrm{d}$ ), the $\mathrm{Pd}$ species mainly exists as fully exposed Pd clusters as highlighted in Supplementary Fig. 2b. Clearly, the Pd species in these two catalysts are both atomically dispersed on the ND@G support $^{24,37,38}$.

X-ray absorption near-edge structure (XANES) and extended $\mathrm{X}$-ray absorption fine structure (EXAFS) measurements were performed to study the electronic structure and coordination environment of $\mathrm{Pd}$ species in $\mathrm{Pd}_{1} / \mathrm{ND} @ \mathrm{G}$ and $\mathrm{Pd}_{n} / \mathrm{ND} @ \mathrm{G}$ catalysts. From XANES results, the valence states of $\mathrm{Pd}_{1} / \mathrm{ND} @ \mathrm{G}$ and $\mathrm{Pd}_{n} / \mathrm{ND} @ \mathrm{G}$ were thoroughly investigated. Notably, the valence state of $\mathrm{Pd}_{\mathrm{n}} / \mathrm{ND} @ \mathrm{G}$ and $\mathrm{Pd}_{1} / \mathrm{ND} @ \mathrm{G}$ are between those of PdO and Pd foil (Fig. 1e), indicating that fully exposed Pd clusters and $\mathrm{Pd}$ single atoms are both slightly positively charged. Meanwhile, the $\mathrm{Pd}$ species in $\mathrm{Pd}_{1} / \mathrm{ND} @ \mathrm{G}$ are more positive charged than that in $\mathrm{Pd}_{n} / \mathrm{ND} @ \mathrm{G} . \mathrm{X}$-ray photoemission spectroscopy (XPS) measurements further confirmed the chemical states of the atomically dispersed Pd catalysts (Supplementary Fig. 3). The binding energy of $\mathrm{Pd} 3 d_{5 / 2}$ in $\mathrm{Pd}_{1} / \mathrm{ND} @ \mathrm{G}$ and $\mathrm{Pd}_{n} / \mathrm{ND} @ \mathrm{G}$ are 335.5 and $335.0 \mathrm{eV}$, respectively. The shifts of binding energy suggest that the valence state of $\mathrm{Pd}$ species in $\mathrm{Pd}_{1} / \mathrm{ND} @ \mathrm{G}$ is more positive than that in $\mathrm{Pd}_{n} / \mathrm{ND} @ \mathrm{G}$, agreeing well with the XANES observations, implying a stronger charge transfer between $\mathrm{Pd}_{1}$ species and the ND@G support.

The EXAFS spectra (Fig. 1f) of $\mathrm{Pd}_{1} / \mathrm{ND} @ \mathrm{G}$ only featured a major peak near $1.5 \AA$ from the first coordination shell of Pd associated with $\mathrm{Pd}-\mathrm{C} / \mathrm{O}$ scattering, indicating the formation of isolated $\mathrm{Pd}$ atom in $\mathrm{Pd}_{1} / \mathrm{ND} @ \mathrm{G}$. For $\mathrm{Pd}_{n} / \mathrm{ND} @ \mathrm{G}$, an additional peak at about $2.4 \AA$ from first shell Pd-Pd coordination emerges, indicating the formation of Pd clusters ${ }^{37,38}$. The trend can also be clearly resolved from the WT of Pd k-edge EXAFS oscillation results (Supplementary Fig. 4) ${ }^{39}$. From the fitting structural parameters (see Supplementary Table 2 and Supplementary Fig. 5), it is obvious that the $\mathrm{Pd}-\mathrm{C} / \mathrm{O}$ coordination number in $\mathrm{Pd}_{1} / \mathrm{ND} @ \mathrm{G}$ was about 2.6, indicating each Pd atom is bonded to three $\mathrm{C} / \mathrm{O}$ atoms. For $\mathrm{Pd}_{n} / \mathrm{ND} @ \mathrm{G}$ catalyst, the $\mathrm{Pd}-\mathrm{C} / \mathrm{O}$ coordination number was 2.5 , while the $\mathrm{Pd}-\mathrm{Pd}$ coordination number was 1.9 , suggesting that the fully exposed Pd cluster was composed by about three Pd atoms on average, agreeing well with the AC-HAADF-STEM images as displayed in Fig. 1 and Supplementary Fig. 2b. From those results, we can conclude that these two catalysts exhibit distinct difference in coordination environment as well as in electronic structure, which will surely affect their reaction behavior in catalytic reaction.

Benzonitrile transfer hydrogenation reaction. Subsequently, the catalytic transfer hydrogenation of benzonitrile (BN) was evaluated over the atomically dispersed $\mathrm{Pd}_{1} / \mathrm{ND} @ \mathrm{G}$ and $\mathrm{Pd}_{n} / \mathrm{ND} @ \mathrm{G}$ catalysts. As shown in Fig. 2a, several products are obtained in the transfer hydrogenation of BN. For the control experiment with pure ND@Gas catalyst, no hydrogenation reaction happened, 


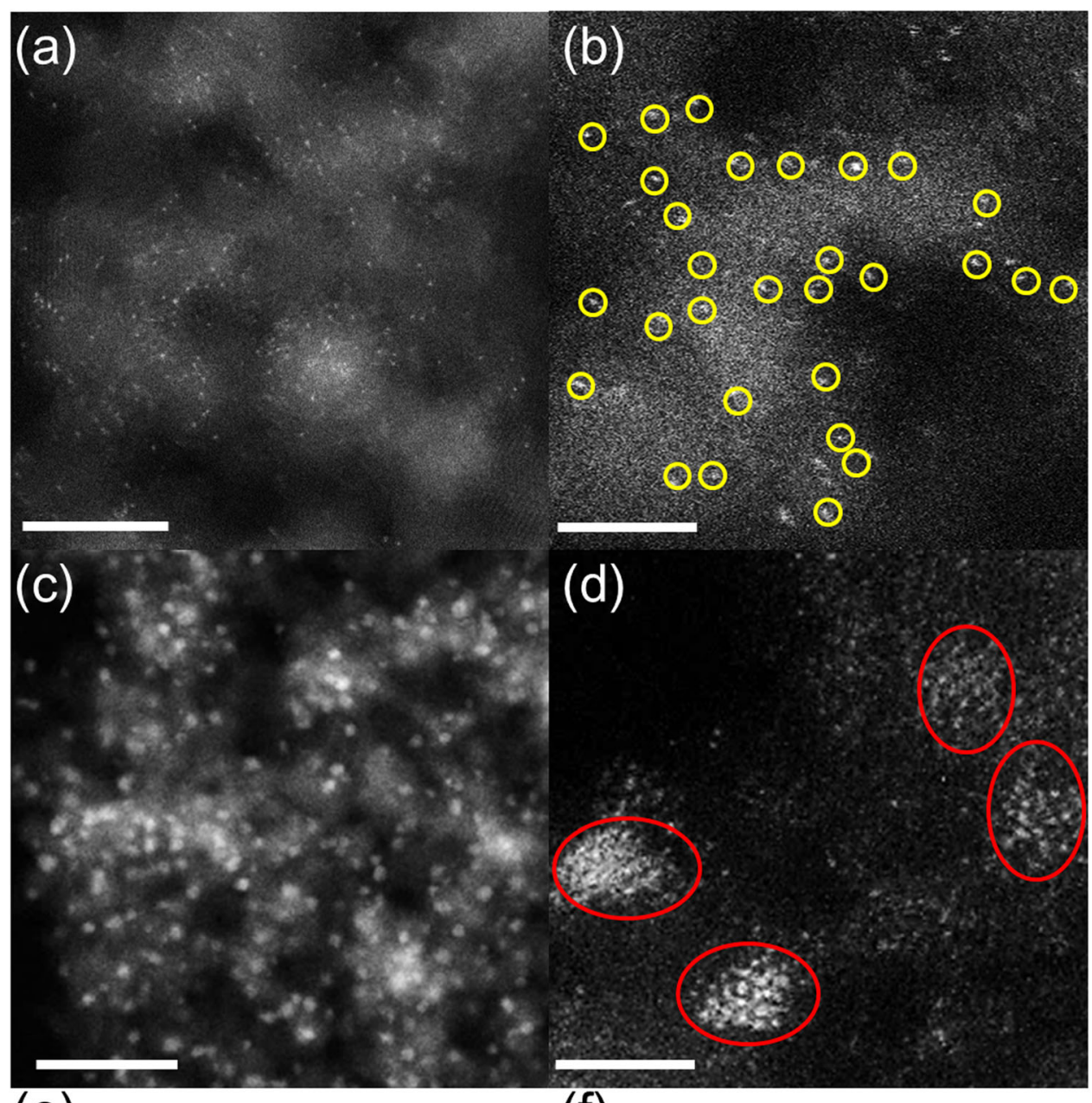

(e)

(f)
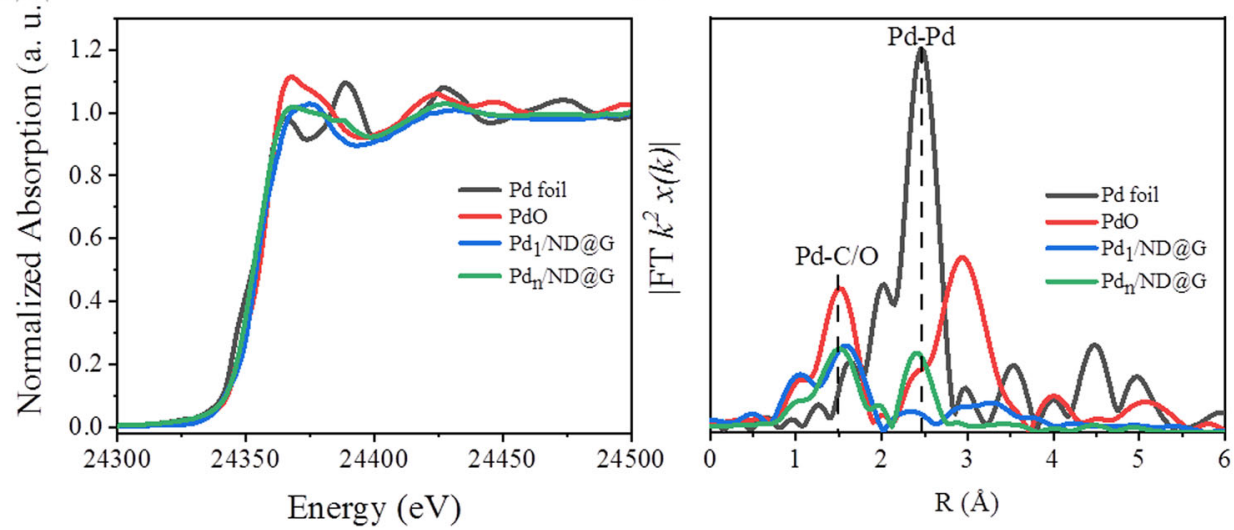

Fig. 1 Structural characterization of catalysts. a HAADF-STEM images of $\mathrm{Pd}_{1} / \mathrm{ND} @ \mathrm{G}$ at low magnification. b Atomically dispersed single Pd atoms in $\mathrm{Pd}_{1} / \mathrm{ND} @ \mathrm{G}$ highlighted by the yellow circles. c HAADF-STEM images of $\mathrm{Pd}_{n} / \mathrm{ND} @ \mathrm{G}$ at low magnification. d Fully exposed Pd clusters in Pd $\mathrm{d}_{n} / \mathrm{ND} @ \mathrm{G}$ highlighted by the red circles. e Pd K-edge XANES profiles and f EXAFS spectra for Pd $1 / N D @ G$ and Pd $n$ /ND@G. Scale bars: a, 5 nm; b, d, 2 nm; c, 20 nm.

indicating that Pd is the active species instead of ND@G (Fig. 2e). Notably, $\mathrm{Pd}_{1} / \mathrm{ND} @ \mathrm{G}$ and $\mathrm{Pd}_{n} / \mathrm{ND} @ \mathrm{G}$ catalysts exhibited different catalytic performances (Fig. 2b, c). For $\mathrm{Pd}_{1} / \mathrm{ND} @ \mathrm{G}$ catalyst under the optimized condition, the BN conversion is close to $100 \%$ after $8 \mathrm{~h}$, producing dibenzylamine (DBA) with $98 \%$ selectivity (see Supplementary Table 3, entry 3 and Supplementary Table 4, entry 2). However, the DBA yield decreased slightly with extended reaction time, demonstrating that a small amount of $\mathrm{DBA}$ is converted to benzylamine (BA) (Fig. 2b). For $\mathrm{Pd}_{n} / \mathrm{ND} @ \mathrm{G}$, $\mathrm{BN}$ could be completely consumed within $0.5 \mathrm{~h}$ (Fig. 2c) (see Supplementary Tables 5 and 6 entry 2), and the BA was primarily obtained (yield to BA above 98\%, Fig. 2e). Further increase in the reaction time to $120 \mathrm{~min}$, no transformation of $\mathrm{BA}$ can be observed, suggesting that it is the most stable product at this reaction condition over the fully exposed Pd cluster catalyst. And the commercial $\mathrm{Pd} / \mathrm{C}$ catalyst was used as a reference (for the detailed structure information see Supplementary Fig. 6), although $\mathrm{Pd} / \mathrm{C}$ catalyst also exhibited higher selectivity of $\mathrm{BA}$, the catalyst activity was much worse compared with the fully exposed cluster $\mathrm{Pd}_{n} / \mathrm{ND} @ \mathrm{G}$ catalyst (Fig. 2e). 
(a)

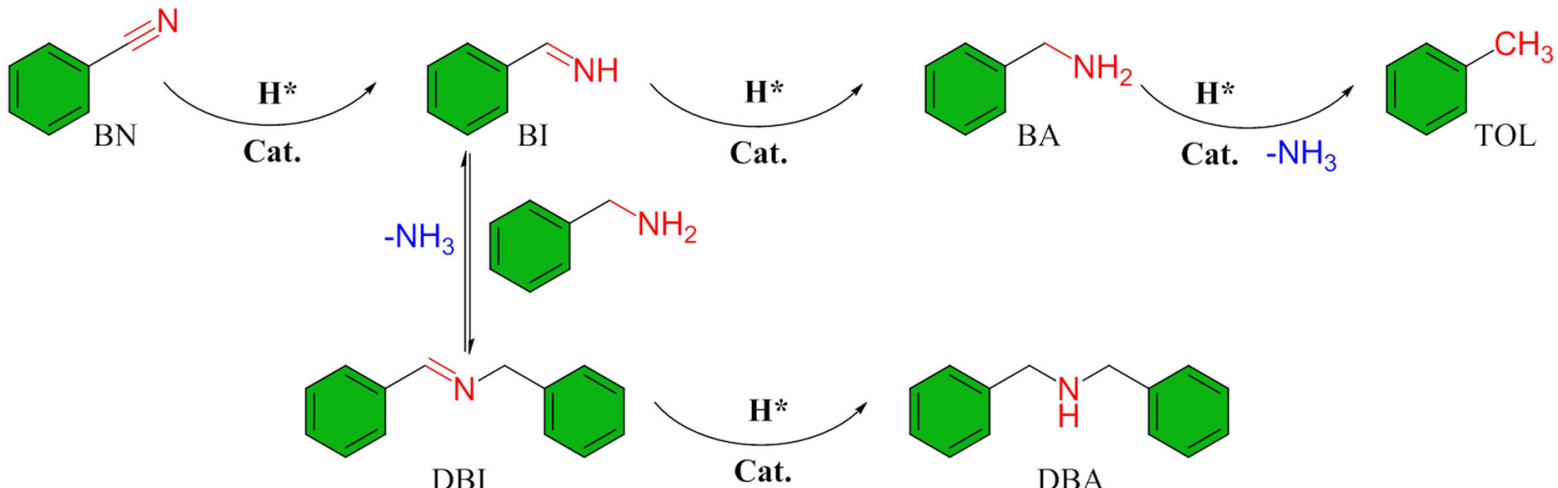

(b)

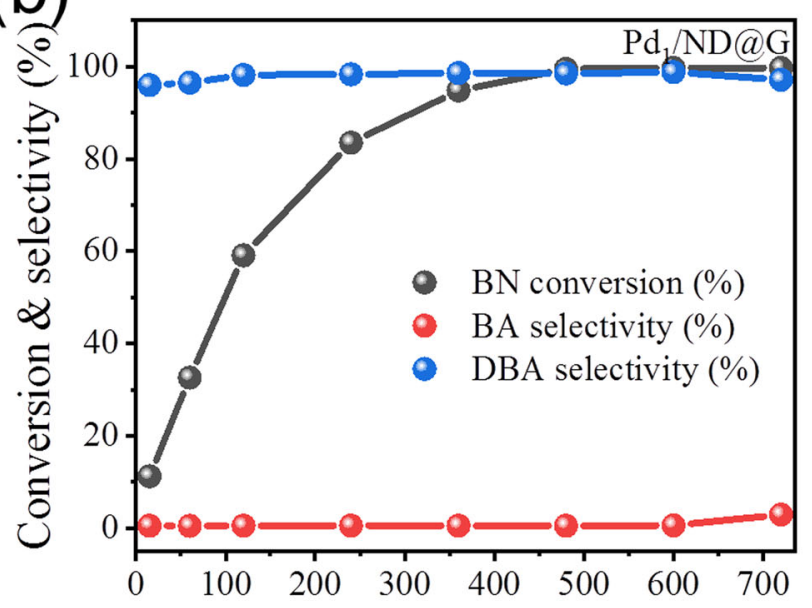

(d)

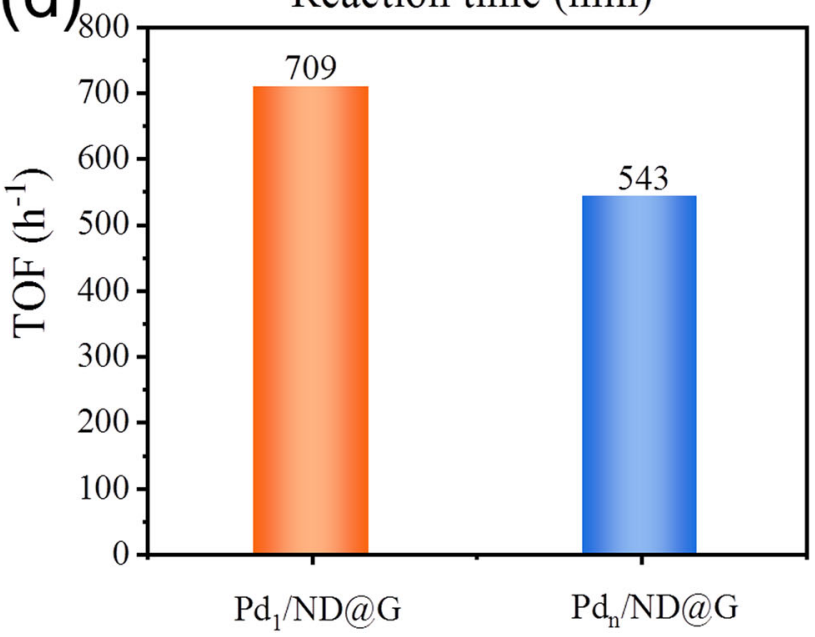

(c)
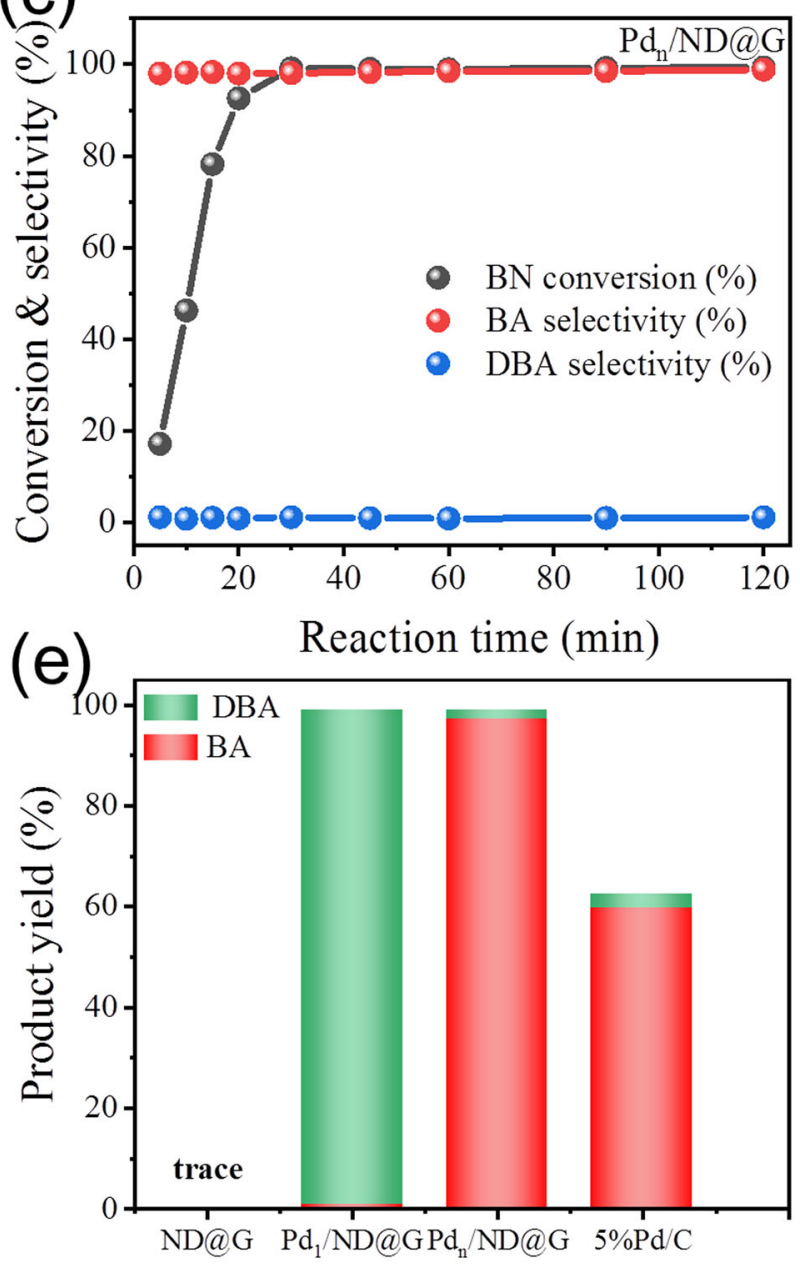

Fig. 2 Catalytic performances of Pd1/ND@G and Pdn/ND@G catalysts in transfer hydrogenation of benzonitrile. a Possible reaction scheme in the transfer hydrogenation of benzonitrile yielding benzylamine, $\mathrm{N}$-benzylidenebenzylamine, and dibenzylamine. $\mathbf{b}$ Time-conversion plot for production formation from the transfer hydrogenation of benzonitrile over Pd $1 / N D @ G$. Reaction conditions: solvent, methanol, 10 mL; BN, 0.5 mmol; catalyst, 30 mg; $\mathrm{AB}, 4 \mathrm{mmol}$; temperature, $60^{\circ} \mathrm{C}$. c Time-conversion plot for production formation from the transfer hydrogenation of benzonitrile over Pd $/ \mathrm{ND} @ \mathrm{G}$.

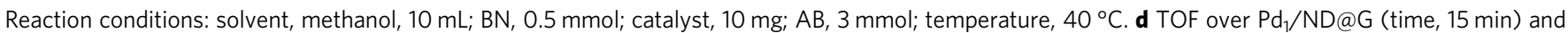

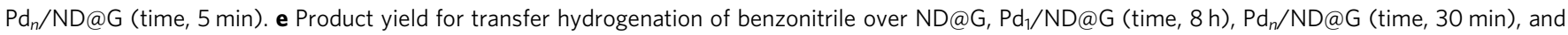
$\mathrm{Pd} / \mathrm{C}$ (time, $30 \mathrm{~min}$ ). 
The catalytic performance results show that the transfer hydrogenation of $\mathrm{BN}$ is drastically different over the atomically dispersed $\mathrm{Pd}_{1} / \mathrm{ND} @ \mathrm{G}$ and $\mathrm{Pd}_{n} / \mathrm{ND} @ \mathrm{G}$ catalysts. $\mathrm{BN}$ shows high selectivity to secondary amines DBA over the single Pd atoms, while the fully exposed $\mathrm{Pd}$ clusters can selectively convert the $\mathrm{BN}$ to primary amines BA. As shown in Fig. 2d, the TOF@333 K of $\mathrm{Pd}_{1} / \mathrm{ND} @ \mathrm{G}$ and the TOF@313 $\mathrm{K}$ of $\mathrm{Pd}_{n} / \mathrm{ND} @ \mathrm{G}$ is 709 and $543 \mathrm{~h}^{-1}$, respectively. The performance evaluation of the catalyst after the reaction was further evaluated; the activity of the $\mathrm{Pd}_{1} / \mathrm{ND} @ \mathrm{G}$ catalyst was partially reduced. However, the $\mathrm{Pd}_{1} / \mathrm{ND} @ \mathrm{G}$ catalyst still retains good selectivity of DBA (Supplementary Fig. 7e) and suggests that the $\mathrm{Pd}$ single atoms still play a major role. As shown in Supplementary Fig. 7f, there was no significant change in activity of $\mathrm{Pd}_{n} / \mathrm{ND} @ \mathrm{G}$ catalyst after reaction, but the selectivity of DBA increased slightly. AC-HAADF-STEM measurements of the two catalysts after reaction further confirmed the leaching of a few Pd atoms leads to the decrease of the density of metal $\mathrm{Pd}$ in the $\mathrm{Pd}_{1} / \mathrm{ND} @ \mathrm{G}$ catalyst after reaction (Supplementary Fig. 7a, b). And performance change of $\mathrm{Pd}_{n} / \mathrm{ND} @ \mathrm{G}$ catalyst may be related to the decrease in the number of clusters and increase in the number of single atoms caused by the leaching of $\mathrm{Pd}$ in the $\mathrm{Pd}_{n} / \mathrm{ND} @ \mathrm{G}$ catalyst (Supplementary Fig. 7c, d). Compared with previously reported catalytic systems, the as-prepared atomically dispersed $\mathrm{Pd}$ catalysts both show robust catalytic performance to corresponding amines under mild reaction conditions (see Supplementary Table 7).

Substrate extension. The reaction has been expanded to broad scopes of nitriles over the $\mathrm{Pd}_{1} / \mathrm{ND} @ \mathrm{G}$ and $\mathrm{Pd}_{n} / \mathrm{ND} @ \mathrm{G}$ catalysts, respectively. As shown in Fig. 3, $\mathrm{Pd}_{1} / \mathrm{ND} @ \mathrm{G}$ and $\mathrm{Pd}_{n} / \mathrm{ND} @ \mathrm{G}$ both show superior catalytic performance. As investigated, benzonitriles with electron-donating substituents and electron-withdrawing substrates obtain corresponding amines selectively. Compared with the aromatic nitriles, it was a great challenge to catalytically hydrogenate aliphatic nitriles, because it was less active and the by-products with methyl compounds are easy to produce in the hydrogenation ${ }^{13,40}$. Herein, phenylacetonitrile was taken as representatives and their catalytic hydrogenation over the $\mathrm{Pd}_{1} / \mathrm{ND} @ \mathrm{G}$ and $\mathrm{Pd}_{n} / \mathrm{ND} @ \mathrm{G}$ catalysts were discussed, respectively. The corresponding primary amines or second amines were acquired and the results were shown in Fig. 3. The results elucidate that the structure sensitivity over these two types of atomically dispersed Pd catalyst in hydrogenation are well kept in general nitriles. In short, our selectivity regulation strategy can be applied to a wide substrate range, and the two catalysts demonstrated a good tolerance to many functional groups.

DFT calculations. DFT calculations were carried out to gain insights into the selectivity regulation and the overall reaction pathways over the $\mathrm{Pd}_{1} / \mathrm{ND} @ \mathrm{G}$ and $\mathrm{Pd}_{n} / \mathrm{ND} @ \mathrm{G}$ catalysts in $\mathrm{BN}$ hydrogenation reaction. According to EXAFS analysis, an isolated $\mathrm{Pd}$ atom, $\mathrm{Pd}_{1}-\mathrm{Graphene}\left(\mathrm{Pd}_{1}-\mathrm{Gr}\right)$, and three-atom Pd cluster on graphene layer, $\mathrm{Pd}_{3}-\mathrm{Graphene}$, were constructed to represent the active sites on $\mathrm{Pd}_{1} / \mathrm{ND} @ \mathrm{G}$ and $\mathrm{Pd}_{n} / \mathrm{ND} @ \mathrm{G}$ catalysts, respectively. As shown in Fig. 4, $\mathrm{H}_{2}$ gas adsorbs physically on $\mathrm{Pd}_{1}-\mathrm{Gr}$ after the adsorption of $\mathrm{BN}$ molecule, which is exothermic by $0.38 \mathrm{eV}$. The activation of adsorbed $\mathrm{H}_{2}$ carried a barrier of $1.15 \mathrm{eV}$ and is endothermic by $0.61 \mathrm{eV}$, with one $\mathrm{H}$ atom adsorbed on the $\mathrm{Pd}$ single atom and one on $\mathrm{C}$ atom (the configuration is shown Supplementary Fig. 8), respectively. Next, the hydrogenation processes of $\mathrm{BN}$ undergo $\mathrm{H}$ transfer after the $\mathrm{H}_{2}$ activation and C-H formation steps (as shown in Supplementary Fig. 8), which

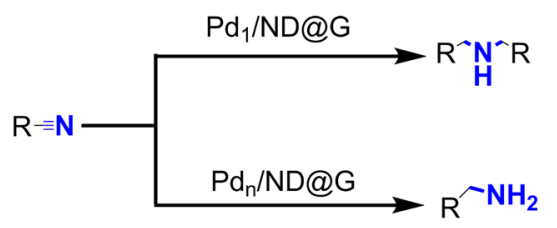

\begin{tabular}{|c|c|c|c|c|c|c|}
\hline \multirow{3}{*}{ Substrate } & \multicolumn{3}{|c|}{$\mathrm{Pd}_{1} / \mathrm{ND} @ \mathrm{G}^{\mathrm{a}}$} & \multicolumn{3}{|c|}{$P d_{n} / N D @ G^{b}$} \\
\hline & \multirow{2}{*}{$\begin{array}{l}t(h) \\
8 h\end{array}$} & Con. (\%) & Sel. (\%) & \multirow{2}{*}{$\begin{array}{l}t(h) \\
0.5 h\end{array}$} & Con. (\%) & Sel. (\%) \\
\hline & & $>99 \%$ & $98 \%$ & & $>99 \%$ & $98 \%$ \\
\hline 2 & $8 \mathrm{~h}$ & $>99 \%$ & $90 \%$ & $0.5 \mathrm{~h}$ & $>99 \%$ & $97 \%$ \\
\hline 3 & $9 \mathrm{~h}$ & $>99 \%{ }^{\mathrm{M}}$ & e $90 \%$ & $1 \mathrm{~h}$ & $>99 \% \mathrm{Me}$ & $98 \%$ \\
\hline $4^{M}$ & $8 \mathrm{~h}$ & $>99 \%{ }^{N}$ & $98 \%$ & $1 \mathrm{~h}$ & $>99 \%$ & $98 \%$ \\
\hline 5 & $10 \mathrm{~h}$ & $>99 \%$ & $85 \%$ & $2 \mathrm{~h}$ & $>99 \%$ & $90 \%$ \\
\hline 6 & $10 \mathrm{~h}$ & $>99 \%$ & $90 \%$ & $3 \mathrm{~h}$ & $>99 \%$ & $90 \%$ \\
\hline$\stackrel{\mathrm{F}}{\mathrm{F}} \mathrm{C}$ & $8 \mathrm{~h}$ & $>99 \% \underset{F}{F}$ & $91 \%$ & $3 \mathrm{~h}$ & $>99 \%$ & $98 \%$ \\
\hline 8 & $11 \mathrm{~h}$ & $>99 \%$ & $98 \%$ & $2 \mathrm{~h}$ & $>99 \%$ & $93 \%$ \\
\hline
\end{tabular}

a Reaction condition: nitriles $(0.5 \mathrm{mmol}), \mathrm{AB} .(4 \mathrm{mmol})$ and catalyst $(30 \mathrm{mg})$ in $10 \mathrm{~mL}$ of $\mathrm{CH}_{3} \mathrm{OH}$ were heated at $60^{\circ} \mathrm{C}$. $\mathrm{GC}$ yield $(\%)$ were shown used $\mathrm{m}$-Xylene as the internal standard.

${ }^{b}$ Reaction condition: nitriles $(0.5 \mathrm{mmol}), \mathrm{AB} .(3 \mathrm{mmol})$ and catalyst $(10 \mathrm{mg})$ in $10 \mathrm{~mL}$ of $\mathrm{CH}_{3} \mathrm{OH}$ were heated at $40^{\circ} \mathrm{C} . \mathrm{GC}$ yield $(\%)$ were shown used $\mathrm{m}$-Xylene as the internal standard.

Fig. 3 Substrate extension. Catalytic performance of $P d_{1} / N D @ G$ and $P d_{n} / N D @ G$ catalyst in transfer hydrogenation of different substituted nitriles. 


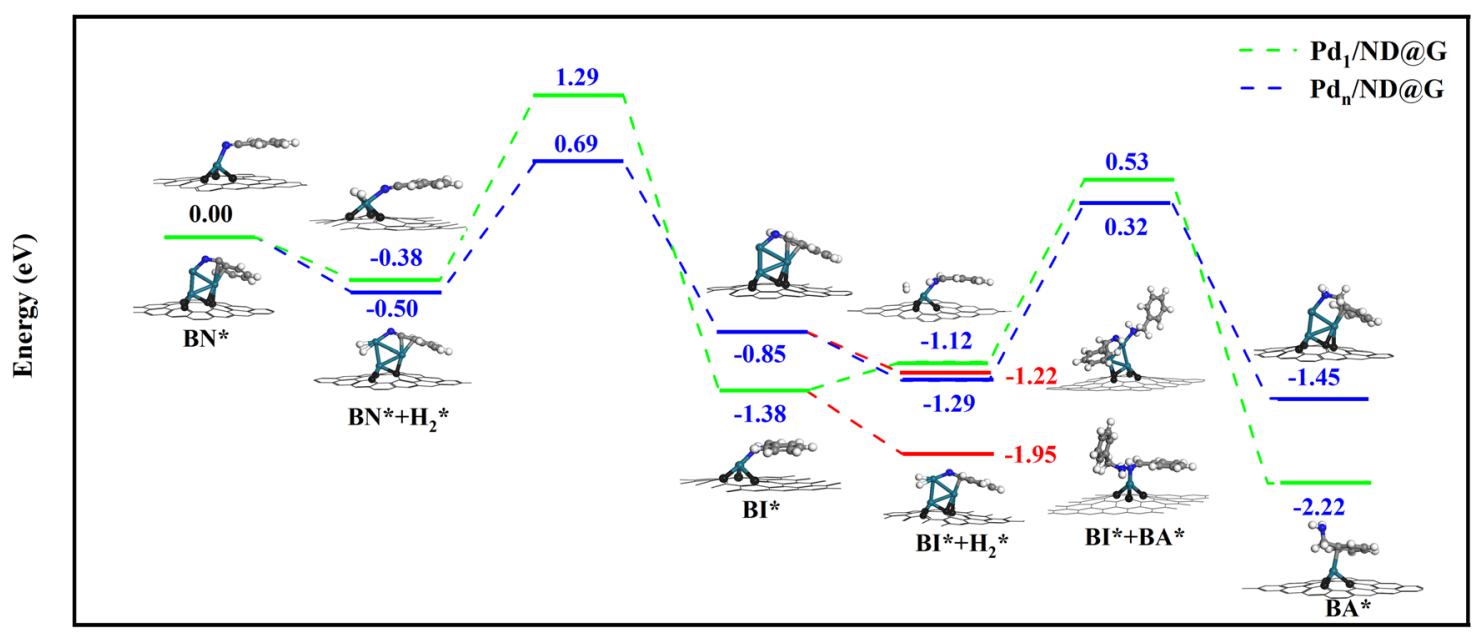

Reaction Coordinate

Fig. 4 Step-by-step hydrogenation mechanism of benzonitrile to benzylamine on Pd1/ND@G and Pdn/ND@G. Color code: Pd $1 / N D @ G(g r e e n ~ l i n e)$ and $\mathrm{Pd}_{n} / \mathrm{ND} @ \mathrm{G}$ (blue line). Pd cyan, $\mathrm{C}$ gray, $\mathrm{H}$ white.

is exothermic by $1.0 \mathrm{eV}$ and has an effective barrier of $1.67 \mathrm{eV}$. The further hydrogenation reaction from BI to BA is a similar process, which is exothermic by $1.1 \mathrm{eV}$ and surfer from a higher effective barrier $1.91 \mathrm{eV}$. However, It should be noted that the dissociative adsorption process of the second $\mathrm{H}_{2}$ is significantly harder thermodynamically and kinetically: the physical adsorption of the second $\mathrm{H}_{2}$ gas is endothermic by $0.26 \mathrm{eV}$ while that of the first $\mathrm{H}_{2}$ is exothermic by $0.38 \mathrm{eV}$; The effective barrier of the second $\mathrm{H}_{2}$ dissociative adsorption is $1.25 \mathrm{eV}$, slightly higher than $1.15 \mathrm{eV}$ of the first $\mathrm{H}_{2}$ gas. These calculated results indicate that the resident time of the $\mathrm{BI}$ surface intermediate is extended on $\mathrm{Pd}_{1}-\mathrm{Gr}$ since the difficult activation of the second $\mathrm{H}_{2}$, which helps the condensation reaction of BI surface intermediate by BA to form the $N$-benzylidenebenzylamine (DBI) intermediate. Then, DBI undergoes hydrogenation processes to generate the product (DBA) on $\mathrm{Pd}_{1}$-Gr. In addition, as shown in Fig. 4 (red lines), we found that the further adsorption of BA after the formation of BI surface intermediate is exothermic by $0.57 \mathrm{eV}$, stronger than that of the second $\mathrm{H}_{2}$ molecule (endothermic by $0.26 \mathrm{eV}$ ), which again suggests that the BI surface intermediates prefer to condensate with $\mathrm{BA}$ to generate the $\mathrm{DBI}$ intermediate than to hydrogenate to obtain BA. The calculated results of $\mathrm{Pd}_{1}-\mathrm{Gr}$ explained well the excellent selectivity of DBA.

On $\mathrm{Pd}_{3}-\mathrm{Graphene}\left(\mathrm{Pd}_{3}-\mathrm{Gr}\right), \mathrm{H}_{2}$ molecule easily dissociates after the adsorption of $\mathrm{BN}$ molecule, which is exothermic by $0.50 \mathrm{eV}$ (see Supplementary Fig. 9). Then, the hydrogenation steps of $\mathrm{BN}$ to $\mathrm{BI}$ process with effective barrier $1.19 \mathrm{eV}$ and is exothermic by $0.35 \mathrm{eV}$. As shown in Supplementary Fig. 9, we can see that the dissociative adsorption of the second $\mathrm{H}_{2}$ gas occurs easily without barriers and is exothermic by $0.44 \mathrm{eV}$, which could boost the hydrogenation of BI intermediates and shorten the resident time of the $\mathrm{BI}$ surface intermediate. The following hydrogenation of $\mathrm{BI}$ to $\mathrm{BA}$ is exothermic by $0.16 \mathrm{eV}$ and has a higher effective barrier of $1.54 \mathrm{eV}$. What is more, Fig. 4 shows the adsorption of BA after the formation of BI intermediates $(-0.37 \mathrm{eV})$ is weaker than the dissociative adsorption of $\mathrm{H}_{2}$ gas on $\mathrm{Pd}_{3}-\mathrm{Gr}(-0.44 \mathrm{eV})$, suggesting that the hydrogenation reaction will be dominant compared to the condensation reaction of $\mathrm{BI}$ with $\mathrm{BA}$. The theoretical studies of $\mathrm{BN}$ hydrogenation on $\mathrm{Pd}_{3}-\mathrm{Gr}$ reveal that the high selectivity of $\mathrm{BA}$ originates from the facile activation of the $\mathrm{H}_{2}$ molecules and the BA weak adsorption after the formation of the BI intermediate. These calculation results are consistent with our experimental results.

\section{Discussion}

In summary, we investigated the structure-performance relationship at atomic scale for hydrogenation of nitriles by employing $\mathrm{Pd}_{1} / \mathrm{NDG}$ with $\mathrm{Pd}$ single atoms and $\mathrm{Pd}_{n} / \mathrm{NDG}$ with fully exposed Pd clusters as the catalyst. The secondary amines ( $>98 \%$ selectivity) and primary amines ( $>98 \%$ selectivity) are selectively generated under mild reaction conditions over $\mathrm{Pd}_{1} /$ NDG and $\mathrm{Pd}_{n} / \mathrm{NDG}$, respectively. Due to high utilization of $\mathrm{Pd}$ in these two atomically dispersed catalysts, excellent reactivity was achieved compared with other catalytic systems. DFT calculation reveals that the intermediate $\mathrm{BI}$ is easier to further hydrogenate to BA on the $\mathrm{Pd}_{n} / \mathrm{NDG}$ catalyst. While on the $\mathrm{Pd}_{1} / \mathrm{NDG}$ catalyst, $\mathrm{BI}$ is more inclined to undergo condensation reaction and continuing hydrogenation to obtain DBA. The selectivity regulation strategy established over these catalysts with atomic precision in structure will pave the way for the rational design and construction of the highly selective catalyst with fully metal utilization efficiency.

\section{Methods}

Materials. Nanodiamond (ND) powders (99.9\%) were purchased from Beijing Grish Hitech Co., and further purified by hydrochloric acid. Pd precursor $\left(\mathrm{Pd}\left(\mathrm{NO}_{3}\right)_{2}\right.$ solution) was analytical regent and purchased from Alfa Aesar without further purification. Benzonitrile was purchased from Alfa Aesar. Ammonia borane was purchased from Macklin.

Preparation of ND@G. ND powder was calcined to obtain ND@G at $1100^{\circ} \mathrm{C}$ (condition: heating rate $5^{\circ} \mathrm{C} \mathrm{min}-1$ for $4 \mathrm{~h}$ under $100 \mathrm{~mL} \mathrm{~min}^{-1}$ flowing Ar gas) and then naturally cooled to room temperature. The as-prepared products were further purified by hydrochloric acid for $24 \mathrm{~h}$ and then washed with DI water. Finally, the as-prepared ND@G support with diamond core and defective graphene shell was obtained after drying in vacuum at $60^{\circ} \mathrm{C}$ for $24 \mathrm{~h}$.

Preparation of $P d_{\mathrm{n}} / N D @ G$ and $P d_{1} / N D @ G$. First, $200 \mathrm{mg} N D @ G$ was dispersed into $30 \mathrm{~mL}$ deionized water in a $100 \mathrm{~mL}$ round-bottom flask, and the mixture was ultrasonically treated to obtain a homogeneous suspension. Then, the $\mathrm{pH}$ value of ND@G supports suspension was adjusted to about 10 by dropping $0.25 \mathrm{M} \mathrm{Na}_{2} \mathrm{CO}_{3}$ solution. Second, a certain amount of $\mathrm{Pd}\left(\mathrm{NO}_{3}\right)_{2}$ solution (containing $0.016 \mathrm{~g} \mathrm{~mL}^{-1}$ Pd, from Alfa Aesar) was diluted into $4 \mathrm{~mL}$ water, and then the $\mathrm{pH}$ value of the solution was adjusted to neutral using $0.25 \mathrm{M} \mathrm{Na}_{2} \mathrm{CO}_{3}$. Subsequently, the $\mathrm{pH}$ neutral Pd solution was introduced immediately to carbon support suspension by drop-wise under magnetic stirring at $100^{\circ} \mathrm{C}$, and then kept stirring at $100^{\circ} \mathrm{C}$ in oil bath for 1 hour. At the end, the mixture was cooled to room temperature, collected by filter, and washed several times with deionized water, until it was free of $\mathrm{Na}^{+}$ and $\mathrm{CO}_{3}{ }^{2-}$. Afterwards, the powders were dried at $60^{\circ} \mathrm{C}$ for $12 \mathrm{~h}$. The as-prepared catalysts were reduced in $\mathrm{H}_{2}\left(10 \mathrm{vol} \% \mathrm{H}_{2}\right.$ in $\mathrm{He}$, flow rate $\left.=20 \mathrm{~mL} \mathrm{~min}^{-1}\right)$ at $200^{\circ} \mathrm{C}$ for $1 \mathrm{~h}$ before the catalytic reaction. 
Characterizations. HRTEM images were taken by a FEI Tecnai G2 F20 working at $200 \mathrm{kV}$. Atomic resolution STEM images were recorded by Cs-corrected cold field-emission. The XRD patterns of the nanocarbon supported Pd catalysts were collected by using an X-ray diffractometer (D/MAX-2400) using a $\mathrm{Cu} \mathrm{Ka}$ source at a scan rate of $2^{\circ} \mathrm{min}^{-1}$. XAFS measurements were carried out at the BL14W1 station in Shanghai Synchroton Radiation Facility (SSRF, $3.5 \mathrm{GeV}$, $250 \mathrm{~mA}$ in maximum, $\mathrm{Si}$ (311) double crystals)

Typical procedure for the synthesis of DBA. $0.5 \mathrm{mmol}$ benzonitrile (from Alfa Aesar), $4 \mathrm{mmol} \mathrm{AB}$ (from Macklin), $1 \mathrm{mmol} m$-xylene (from SCR) as internal standard, $30 \mathrm{mg} \mathrm{Pd} / \mathrm{ND} @ \mathrm{G}$ and $10 \mathrm{~mL}$ methanol were added to a sealed tube $(50 \mathrm{~mL})$ and heated at $60{ }^{\circ} \mathrm{C}$ for $8 \mathrm{~h}$. After quenching, the mixture was analyzed by gas chromatography (GC) with the $m$-xylene as internal standard.

Typical procedure for the synthesis of $B A .0 .5 \mathrm{mmol}$ benzonitrile, $3 \mathrm{mmol} \mathrm{AB}$, $1 \mathrm{mmol} m$-xylene as internal standard, $10 \mathrm{mg} \mathrm{Pd} / \mathrm{ND} @ \mathrm{G}$ and $10 \mathrm{~mL}$ methanol were added to a sealed tube $(50 \mathrm{~mL})$ and heated at $40^{\circ} \mathrm{C}$ for $0.5 \mathrm{~h}$. After quenching, the mixture was analyzed by GC with the $m$-xylene as internal standard.

Analytic methods. The Agilent 7890A gas chromatography instrument, equipped with a crosslinked capillary $\left(19091 \mathrm{~J}-413: 325^{\circ} \mathrm{C}: 30 \mathrm{~m} \times 320 \mu \mathrm{m} \times 0.25 \mu \mathrm{m}\right)$ and a flame ionization detector, was used for the products analysis. The analytic conditions were as follows: The flow rate of the $\mathrm{N}_{2}$ carrier gas was $20 \mathrm{~mL}$ min$^{-1}$, and the injection port temperature was $260^{\circ} \mathrm{C}$. The GC oven temperature program was conducted as follows: The temperature program ranges from r.t. to $60^{\circ} \mathrm{C}$ and held at $60^{\circ} \mathrm{C}$ for $8.5 \mathrm{~min}$. Then the temperature program ranges from 60 to $80^{\circ} \mathrm{C}$ at a heating rate of $25^{\circ} \mathrm{C} \mathrm{min}-1$ and heat preservation at $60^{\circ} \mathrm{C}$ for $4 \mathrm{~min}$. And then temperature program ranges from 80 to $200^{\circ} \mathrm{C}$ at a heating rate of $20^{\circ} \mathrm{C} \mathrm{min}-1$ then held at $200^{\circ} \mathrm{C}$ for $5 \mathrm{~min}$. The detector temperature was set to $280^{\circ} \mathrm{C}$. The content of each compound was determined based on the internal standard.

Benzonitrile conversion and selectivity of BA and DBA and TOF were calculated as the follows:

Benzonitrile conversion : Conv. $=(\mathrm{mol}$ of the benzylamine $) /(\mathrm{mol}$ of inlet benzonitrile $) \times 100 \%$

Selectivity of benzylamine : Selectivity $=($ mol of benzylamine $) /($ mol of converted benzonitrile $) \times 100 \%$

Selectivity of dibenzylamine : Selectivity $=2(\mathrm{~mol}$ of dibenzylamine $) /$ (mol of converted benzonitrile) $\times 100 \%$

TOFs $:$ TOFs $=($ moles of converted nitrile $) /($ moles of total noble metal atoms $\times$ reacton time $)$

Computational details. The spin-polarized calculations were performed by VASP $\operatorname{code}^{41,42}$. The projector augmented wave (PAW) method is adopted to describe interaction between electron and ion ${ }^{43,44}$. The generalized gradient approximation (GGA) and the Perdew-Burke-Ernzerhof functional (PBE) ${ }^{45}$ was used for the exchange and correlation energies. An energy cutoff was set to $400 \mathrm{eV}$. The convergence tolerance for electronic and ionic steps was set to $10^{-5}$ and $0.03 \mathrm{eV}^{-1}$ when optimizing the structure of bulk and surfaces. One carbon atom on the graphene layer $\left(5 \times 5\right.$ unit cells) was removed, and $\mathrm{Pd}_{3}$ cluster and $\mathrm{Pd}$ single atom doped in the carbon defect was used as models based on the EXAFS data. To avoid interaction from adjacent cells, a 20 - $\AA$-thick vacuum layer is used. The $2 \times 2 \times 1$ Monkhorst-Pack k-point is set for the models, and the Gaussian smearing method is used with $\sigma=0.1 \mathrm{eV}$. The potential configurations of adsorbed reactants and intermediates were screened to find the most stable one. The transition states (TS) searching method based on constrained $\operatorname{scan}^{46}$ was conducted here. Frequency calculations were performed to verify TS with only on imaginary frequency. Moreover, TS structure with slight displacement towards vibration direction was further optimized in order to verify the identity of TS. Simplified model-based IGRRHO approaches were adopted to estimate the entropy contributions of adsorption and desorption process in the solution in the free energy calculations ${ }^{47}$. We assumed that the translational entropy is mostly responsible for the entropy contribution. The translational entropy of molecules at $40^{\circ} \mathrm{C}$ (reaction condition were calculated using Gaussian 09 package (the IGRRHO is default) ${ }^{48}$. It was estimated that BA molecules and $\mathrm{H}_{2}$ molecules lost 0.58 and $0.39 \mathrm{eV}$ of entropic energy $\left(T^{*} S\right)$ in the adsorption, respectively.

\section{Data availability}

The data supporting this article and other findings are available from the corresponding authors upon request. Source data are provided with this paper.

Received: 22 April 2021; Accepted: 27 September 2021; Published online: 26 October 2021

\section{References}

1. Salvatore, R. N., Yoon, C. H. \& Jung, K. W. Synthesis of secondary amines. Tetrahedron Lett. 57, 7785-7811 (2001).

2. Muller, T. E. \& Beller, M. Metal-initiated amination of alkenes and alkynes. Chem. Rev. 98, 675-703 (1998).

3. Das, K. et al. Platinum-catalyzed direct amination of allylic alcohols with aqueous ammonia: selective synthesis of primary allylamines. Angew. Chem. Int. Ed. 51, 150-154 (2012).

4. Gross, T., Seayad, A. M., Ahmad, M. \& Beller, M. Synthesis of primary amines: first homogeneously catalyzed reductive amination with ammonia. Org. Lett. 4, 2055-2058 (2002).

5. Mueller, T. E., Hultzsch, K. C., Yus, M., Foubelo, F. \& Tada, M. Hydroamination: direct addition of amines to alkenes and alkynes. Chem. Rev. 108, 3795-3892 (2008).

6. Krupka, J. \& Pasek, J. Nitrile hydrogenation on solid catalysts-new Insights into the reaction mechanism. Curr. Org. Chem. 16, 988-1004 (2012).

7. Gomez, S., Peters, J. A. \& Maschmeyer, T. The reductive amination of aldehydes and ketones and the hydrogenation of nitriles: mechanistic aspects and selectivity control. Adv. Synth. Catal. 344, 1037-1057 (2002).

8. Bagal, D. B. \& Bhanage, B. M. Recent advances in transition metal-catalyzed hydrogenation of nitriles. Adv. Synth. Catal. 357, 883-900 (2015).

9. Chong, S. C. \& Lee, B. N. Hydrogenation of nitriles with iridium triphenylphosphine complexes. Catal. Lett. 14, 135-140 (1992).

10. Giannandrea, R., Mastrorilli, P., Zaccaria, G. \& Francesco, N. C. Hydrogenation of organic substrates by isocyanide polymer-bound $\mathrm{Rh}\left(\mathrm{PPh}_{3}\right)_{3}$ Cl. J. Mol. Catal. A 109, 113-117 (1996).

11. Reguillo, R., Grellier, M., Vautravers, N., Vendier, L. \& Sabo-Etienne, S. Ruthenium-catalyzed hydrogenation of nitriles: insights into the mechanism. J. Am. Chem. Soc. 132, 7854-7855 (2010).

12. Rajesh, K., Dudle, B., Blacque, O. \& Berke, H. Homogeneous hydrogenations of nitriles catalyzed by rhenium complexes. Adv. Synth. Catal. 353, 1479-1484 (2011).

13. Zhang, Y., Yang, H., Chi, Q. \& Zhang, Z. Nitrogen-doped carbon-supported nickel nanoparticles: a robust catalyst to bridge the hydrogenation of nitriles and the reductive amination of carbonyl compounds for the synthesis of primary amines. ChemSusChem 12, 1246-1255 (2019).

14. Zen, Y.-F. et al. Robust hydrogenation of nitrile and nitro groups to primary amines using $\mathrm{Ni}_{2} \mathrm{P}$ as a catalyst and ammonia borane under ambient conditions. Asian J. Org. Chem. 6, 1589-1593 (2017).

15. Long, J., Shen, K. \& Li, Y. Bifunctional N-doped Co@C catalysts for base-free transfer hydrogenations of nitriles: controllable selectivity to primary amines vs imines. ACS Catal. 7, 275-284 (2016).

16. Göksu, H. et al. Tandem dehydrogenation of ammonia borane and hydrogenation of nitro/nitrile compounds catalyzed by graphene-supported NiPd alloy nanoparticles. ACS Catal. 4, 1777-1782 (2014).

17. Segobia, D. J., Trasarti, A. F. \& Apesteguía, C. R. Hydrogenation of nitriles to primary amines on metal-supported catalysts: highly selective conversion of butyronitrile to n-butylamine. Appl. Catal. A 445-446, 69-75 (2012).

18. Vile, G. et al. A stable single-site palladium catalyst for hydrogenations. Angew. Chem. Int. Ed. 54, 11265-11269 (2015).

19. Mori, K., Taga, T. \& Yamashita, H. Isolated single-atomic Ru catalyst bound on a layered double hydroxide for hydrogenation of $\mathrm{CO}_{2}$ to formic acid. ACS Catal. 7, 3147-3151 (2017).

20. Chen, F., Jiang, X., Zhang, L., Lang, R. \& Qiao, B. Single-atom catalysis: bridging the homo- and heterogeneous catalysis. Chin. J. Catal. 39, 893-898 (2018).

21. Zhang, $\mathrm{X}$. et al. A stable low-temperature $\mathrm{H}_{2}$-production catalyst by crowding Pt on alpha-MoC. Nature 589, 396-401 (2021).

22. Yang, $\mathrm{M}$. et al. A common single-site $\mathrm{Pt}(\mathrm{II})-\mathrm{O}(\mathrm{OH}) \mathrm{x}$ - species stabilized by sodium on "active" and "inert" supports catalyzes the water-gas shift reaction. J. Am. Chem. Soc. 137, 3470-3473 (2015).

23. Peng, M. et al. Fully exposed cluster catalyst (FECC): toward rich surface sites and full atom utilization efficiency. ACS Cent. Sci. 7, 262-273 (2020).

24. Rossell, M. D. et al. Magnetite-supported palladium single-atoms do not catalyse the hydrogenation of alkenes but small clusters do. Catal. Sci. Technol. 6, 4081-4085 (2016).

25. Zhang, J. et al. Tin-assisted fully exposed platinum clusters stabilized on defect-rich graphene for dehydrogenation reaction. ACS Catal. 9, 5998-6005 (2019).

26. Cheng, N. et al. Platinum single-atom and cluster catalysis of the hydrogen evolution reaction. Nat. Commun. 7, 1 (2016)

27. Kwak, J. H., Kovarik, L. \& Szanyi, J. $\mathrm{CO}_{2}$ reduction on supported $\mathrm{Ru} / \mathrm{Al}_{2} \mathrm{O}_{3}$ catalysts: cluster size dependence of product selectivity. ACS Catal. 3, 2449-2455 (2013)

28. Serna, P. \& Gates, B. C. Zeolite-supported rhodium complexes and clusters: switching catalytic selectivity by controlling structures of essentially molecular species. J. Am. Chem. Soc. 133, 4714-4717 (2011). 
29. Grundner, S. et al. Single-site trinuclear copper oxygen clusters in mordenite for selective conversion of methane to methanol. Nat. Commun. 6, 7546 (2015).

30. Serna, P. et al. Single-site vs. cluster catalysis in high temperature oxidations. Angew. Chem. Int. Ed. 60, 15954-15962 (2021).

31. Zhang, L. et al. Stabilization of palladium nanoparticles on nanodiamondgraphene core-shell supports for CO oxidation. Angew. Chem. Int. Ed. 54, 15823-15826 (2015).

32. Huang, F. et al. Anchoring $\mathrm{Cu}_{1}$ species over nanodiamond-graphene for semihydrogenation of acetylene. Nat. Commun. 10, 4431 (2019).

33. Huang, F. et al. Atomically dispersed Pd on danodiamond/graphene hybrid for selective hydrogenation of acetylene. J. Am. Chem. Soc. 140, 13142-13146 (2018).

34. Liu, L. et al. Pd-CuFe catalyst for transfer hydrogenation of nitriles: controllable selectivity to primary amines and secondary amines. Iscience 8, 61-73 (2018).

35. Yu, C. et al. CuNi nanoparticles assembled on graphene for catalytic methanolysis of ammonia borane and hydrogenation of nitro/nitrile compounds. Chem. Mater. 29, 1413-1418 (2017)

36. Liu, J. et al. Origin of the robust catalytic performance of nanodiamond graphene-supported Pt nanoparticles used in the propane dehydrogenation reaction. ACS Catal. 7, 3349-3355 (2017).

37. Chen, Z. P. et al. A heterogeneous single-atom palladium catalyst surpassing homogeneous systems for Suzuki coupling. Nat. Nanotechnol. 13, 702-707 (2018).

38. Yan, H. et al. Single-atom $\mathrm{Pd}_{1} /$ graphene catalyst achieved by atomic layer deposition: remarkable performance in selective hydrogenation of 1,3Butadiene. J. Am. Chem. Soc. 137, 10484-10487 (2015).

39. Funke, H., Scheinost, A. C. \& Chukalina, M. Wavelet analysis of extended x-ray absorption fine structure data. Phys. Rev. B 71, 094110 (2005).

40. Brieger, G. \& Nestrick, T. J. Catalytic transfer hydrogenation. Chem. Rev. 74, 567-580 (1974).

41. Kresse, G. \& Joubert, D. From ultrasoft pseudopotentials to the projector augmented-wave method. Phys. Rev. B 59, 1758-1775 (1999).

42. Kresse, G. \& Furthmuller, J. Efficiency of ab-initio total energy calculations for metals and semiconductors using a plane-wave basis set. Comp. Mater. Sci. 6, 15-50 (1996)

43. Kresse, G. \& Furthmuller, J. Efficient iterative schemes for ab initio total-energy calculations using a plane-wave basis set. Phys. Rev. B 54, 11169-11186 (1996).

44. Blochl, P. E. Projector augmented-wave method. Phys. Rev. B 50, 17953-17979 (1994).

45. Perdew, J. P., Burke, K. \& Ernzerhof, M. Generalized gradient approximation made simple. Phys. Rev. Lett. 78, 1396-1396 (1997).

46. Plessow, P. N. Efficient transition state optimization of periodic structures through automated relaxed potential energy surface scans. J. Chem. Theroy. Comput 14, 981-990 (2018)

47. Heidar-Zadeh, F. et al. Information-theoretic approaches to atoms-inmolecules: Hirshfeld family of partitioning schemes. J. Phys. Chem. A 122, 4219-4245 (2018).

48. Frisch, M. J. et al. Gaussian 09 (Gaussian, Inc., 2009).

\section{Acknowledgements}

This work was supported by the Ministry of Science and Technology (2016YFA0204100, 2017YFB0602200), the National Natural Science Foundation of China (21961160722,
22072162, 91845201, 21703261, 21725301, 91645115, and 21821004), the Liaoning Revitalization Talents Program XLYC1907055, Dalian National Lab for Clean Energy, DNL Cooperation Fund 202001 and the Sinopec China. N.W. hereby acknowledges the funding support from the Research Grants Council of Hong Kong (Project Nos. C602114E, N_HKUST624/19 and 16306818). The XAS experiments were conducted in Shanghai Synchrotron Radiation Facility (SSRF).

\section{Author contributions}

H.L., D.M. and H.S. conceived the research. Z.L. and F.H. conducted material synthesis and carried out the catalytic performance test. M.P. conducted the X-ray absorption fine structure spectroscopic measurements and analyzed the data. Y.C. and X.W. performed the DFT calculations. X.C. and N.W. contributed to the aberration-corrected high-angle annular dark-field scanning transmission electron microscopy. L.W. and Z.H. performed some of the experiments. The manuscript was primarily written by, Z.L., F.H., H.S., H.J., D.X., H.L., and D.M. All authors contributed to discussions and manuscript review.

\section{Competing interests}

The authors declare no competing interests.

\section{Additional information}

Supplementary information The online version contains supplementary material available at https://doi.org/10.1038/s41467-021-26542-y.

Correspondence and requests for materials should be addressed to Hongbin Sun, Hongyang Liu or Ding Ma.

Peer review information Nature Communications thanks the anonymous reviewers for their contribution to the peer review of this work. Peer reviewer reports are available.

Reprints and permission information is available at http://www.nature.com/reprints

Publisher's note Springer Nature remains neutral with regard to jurisdictional claims in published maps and institutional affiliations.

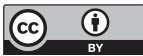

Open Access This article is licensed under a Creative Commons Attribution 4.0 International License, which permits use, sharing, adaptation, distribution and reproduction in any medium or format, as long as you give appropriate credit to the original author(s) and the source, provide a link to the Creative Commons license, and indicate if changes were made. The images or other third party material in this article are included in the article's Creative Commons license, unless indicated otherwise in a credit line to the material. If material is not included in the article's Creative Commons license and your intended use is not permitted by statutory regulation or exceeds the permitted use, you will need to obtain permission directly from the copyright holder. To view a copy of this license, visit http://creativecommons.org/ licenses/by/4.0/.

(C) The Author(s) 2021 